\title{
Dissimilar FSW of Immiscible Materials:
}

\section{Steel/Magnesium}

\author{
H. Kasai, Y. Morisada, H. Fujii \\ Joining and Welding Research Institute, Osaka University \\ Ibaraki, Osaka 567-0047, Japan \\ TEL: +81-06-6879-8663 \\ FAX: +81-06-6879-8663 \\ e-mail: kasai@jwri.osaka-u.ac.jp
}

\section{Abstract}

The dissimilar joint between a light metal and a strong metal such as steel, is necessary for reducing the weight of vehicles. Friction Stir Welding (FSW) is a useful process to obtain several kinds of dissimilar joints and many studies have already been reported. However, the joint between steel and magnesium has not been aggressively studied, because it is an immiscible system. Aluminum is one of the most popular alloying elements for magnesium, and the iron - aluminum system has many intermetallic 
compounds due to their strong interactions. In this study, the $\mathrm{Fe}-\mathrm{Al}$ intermetallic compound layer was successfully formed at the joint interface between iron and magnesium using aluminum in the magnesium alloys. The joint strength increased with the increasing aluminum content of the magnesium alloy due to the depletion of aluminum at the magnesium side near the interface.

Keywords: Friction stir welding; Dissimilar joint; Steel; Magnesium;

Aluminum

\section{Introduction}

Recently, much attention has been paid to emitting less carbon dioxide, and reducing the weight of vehicles is one of the efficient countermeasures [1]. Therefore, the aggressive use of light metals is desired in order to solve these environmental issues. On the other hand, all of the structures require sufficient strength to assure their safety. The dissimilar joint between light metal and strong metal such as steel, is necessary to meet these demands. Aluminum and magnesium are popular light metals, and steels are widely 
used for the structural components due to their high absolute strength and good cost efficiency. As is well known, Friction Stir Welding (FSW) is a useful process to obtain several kinds of dissimilar joints and many studies have already been reported [2-9]. For example, the joint between steel and aluminum had a nearly equal strength as the base aluminum by FSW [10, 11]. Based on the $\mathrm{Fe}$ - $\mathrm{Al}$ phase diagram [12], the iron - aluminum system has many intermetallic compounds due to their strong interactions as shown in Fig. 1(a). On the other hand, the joint between steel and magnesium alloy has not been aggressively studied, although magnesium can efficiently reduce the weight of vehicles due to its lower density than aluminum.

(a)

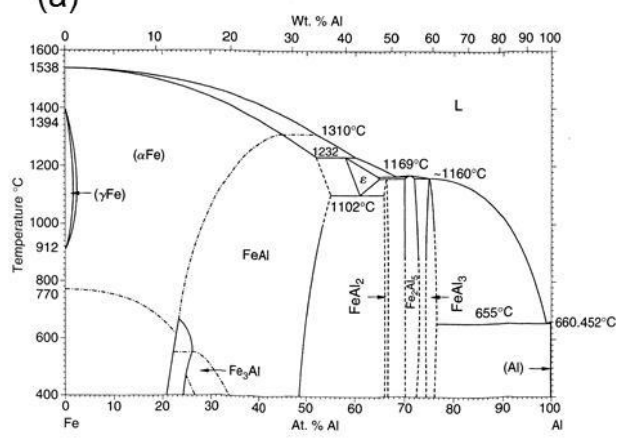

(b)
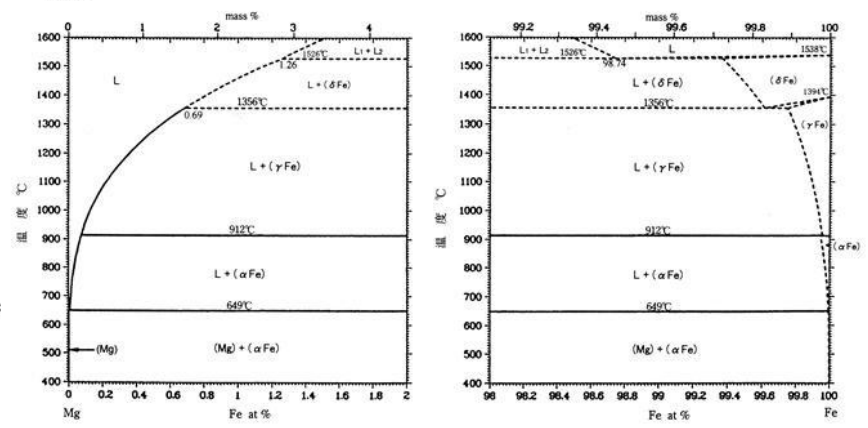

Fig. 1. Fe - $\mathrm{Al}$ and $\mathrm{Fe}-\mathrm{Mg}$ phase diagrams. 
However, the formation of the joint between steel and magnesium is very difficult [13-15]. As shown in Fig. 1(b), the iron - magnesium system is immiscible due to their weak interactions [16]. Therefore, in this study, the alloying elements were evaluated for joining these immiscible materials. There are many alloying elements for magnesium, but aluminum is the most popular element as it is listed in the AZ series alloys. Therefore, the effect of adding aluminum to magnesium on the joint strength of the dissimilar joint between steel and magnesium was investigated in this study.

\section{Experimental procedure}

The specimens were pure magnesium (99.9\% purity), AZ magnesium series alloys and low carbon steel plates which had a thickness of $2 \mathrm{~mm}$, a width of $75 \mathrm{~mm}$ and a length of $300 \mathrm{~mm}$. AZ31 (Mg-2.9wt\%Al-1.05wt\%Zn) and AZ61 (Mg-5.8wt\%Al-0.85wt\%Zn) containing aluminum were used as the magnesium alloys in this study. The average tensile strength of the pure magnesium, AZ31 and AZ61 plates are $170 \mathrm{MPa}, 260 \mathrm{MPa}$ and $280 \mathrm{MPa}$, 
respectively. The effect of aluminum on the mechanical properties of the friction stir welded steel/magnesium joint was investigated by varying the aluminum content in the magnesium. The iron specimen was a low carbon steel plate $(\mathrm{Fe}-0.04 \mathrm{wt} \% \mathrm{C})$. Its average tensile strength is $316 \mathrm{MPa}$. The FSW was conducted using a rotation tool which had a shoulder diameter of $12 \mathrm{~mm}$, a probe diameter of $4 \mathrm{~mm}$ and no threads. The tool was made of WC [17]. The tool tilt angle was 3 degrees. The tool rotation speeds were varied between 250 and 3000rpm, and the welding speed was maintained constant at $100 \mathrm{~mm} / \mathrm{min}$.

The schematic arrangement of the FSW process for obtaining the dissimilar joints is shown in Fig. 2. In order to clarify the appropriate offset position of the rotation tool, the traveling direction of the tool was 0.6 degrees inclined from the butt surface so that the offset position was varied between -0.7 and $2.0 \mathrm{~mm}[10,18]$. In this study, zero is at the position where the probe plunged into the magnesium plate as it just touches the butt face, and plus is at the position where the probe enters into the steel plate, while minus is at the position where the probe enters into the magnesium plate 
$[19,20]$.

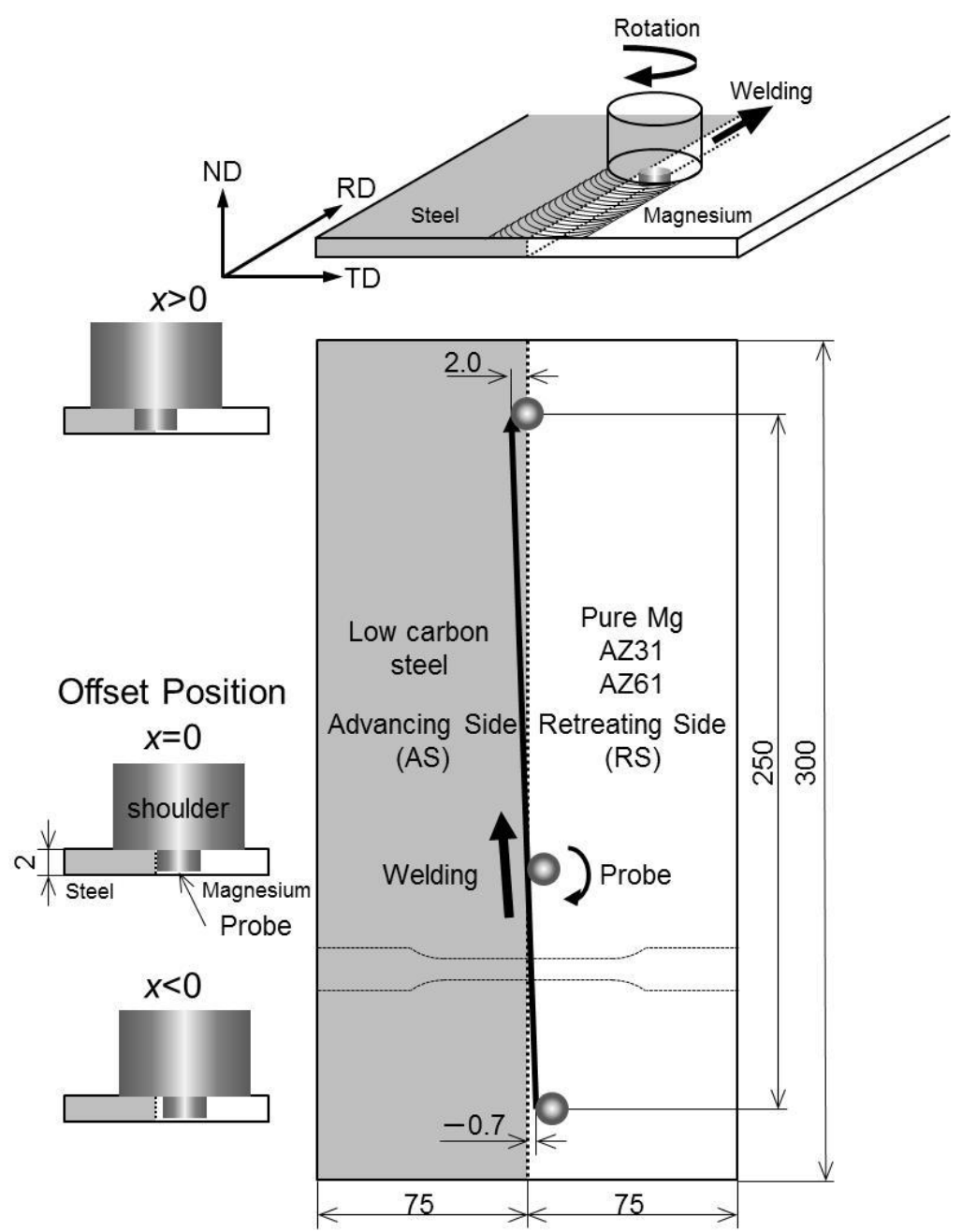

Fig. 2. Schematic illustrations of applied friction stir welding process.

A tensile test was conducted using the test specimens in which tensile the direction was perpendicular to the welding direction. In order to remove the flash formation from the top surface, the specimens were cut about $0.5 \mathrm{~mm}$ from the top and bottom surface. The gage section of the tensile specimens 
had a thickness of $1.5 \mathrm{~mm}$, a width of $8 \mathrm{~mm}$ and a length of $60 \mathrm{~mm}$. Tensile tests were conducted at a constant crosshead speed of $3.6 \mathrm{mmmin}^{-1}$. Metallographic observations were conducted using an optical microscope (OM, Olympus BX51 M microscope), a scanning electron microscope (SEM, JEOL JSM-7001FA SEM) and a transmission electron microscope (TEM, JEOL JEM-2100F TEM). The specimens for the OM observation were first mechanically polished with abrasive paper up to 1000 grits followed by a final polish with $0.1 \mu \mathrm{m} \mathrm{Al}_{2} \mathrm{O}_{3}$ suspensions. The specimens for the SEM observation were polished using a JEOL IB-09020CP cross section polishing (CP) instrument. The thin films with about a 100nm thickness for the TEM observations were prepared using a JEOL JIB-4500 focused ion beam (FIB) instrument and were observed using a JEOL JEM-2100F TEM. Energy dispersive X-ray spectroscopy (EDS) with SEM and TEM was carried out for one hour to observe the intermetallic compound and fracture surface. 


\section{Results and discussion}

\subsection{Effect of FSW conditions on tensile strength}

Figure 3 shows the relationship between the tensile strength and tool offset position at the tool rotation speed of 1000rpm. The joint between the steel and all types of magnesium alloys showed the optimal high tensile strength with an offset ranging from +0.1 to $+1.1 \mathrm{~mm}$. At higher tool rotation speeds, the appropriate offset position was same as those at 1000rpm.

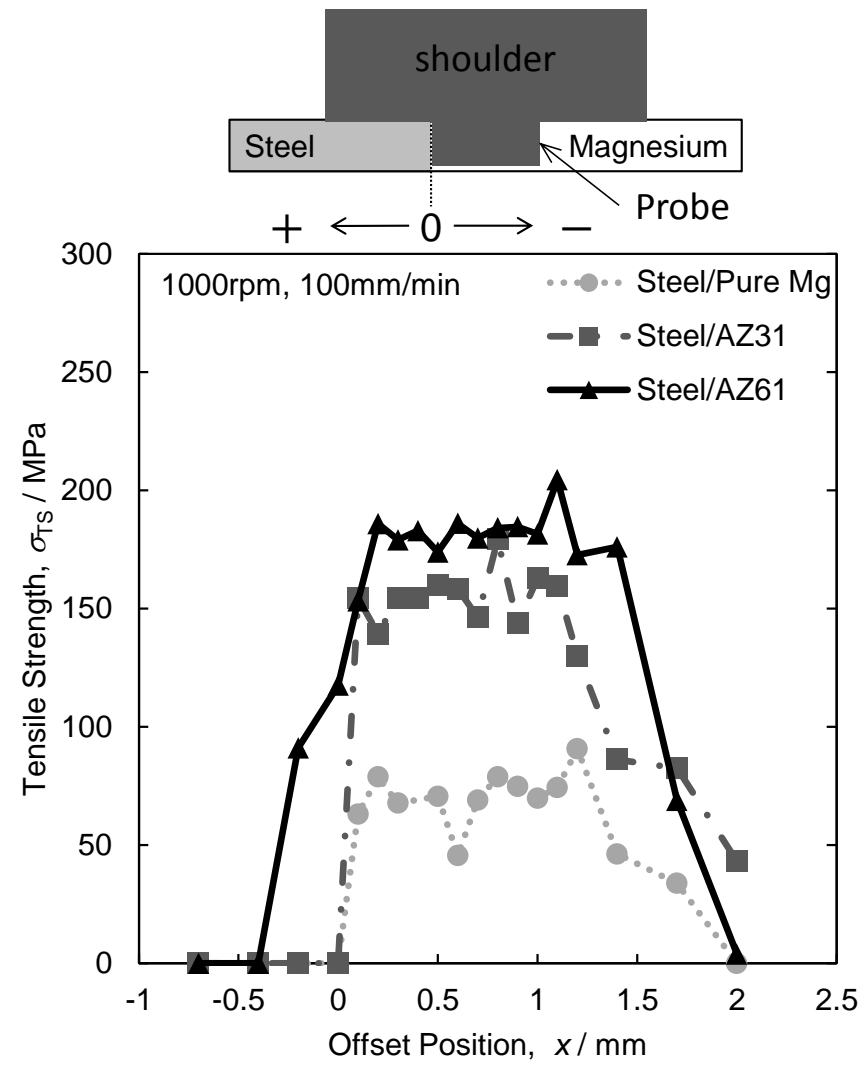

Fig. 3. Relationship between joint tensile strength and tool offset position. (1000rpm, 100mm/min) 
When the offset position was too large plus, some voids were formed in the stir zone (SZ). In contrast, when the offset position was minus, an intermetallic compound layer cannot form as shown later. Therefore, it is considered that the tool probe must come into contact with the steel butt face to join the steel to magnesium.

Figure 4 shows the relationship between the optimal tensile strength and aluminum content at the tool offset position of $+0.5 \mathrm{~mm}$. The joint strength increased with the increasing aluminum content of the magnesium. However, although the aluminum in magnesium increased the strength of the joined interface, all the tensile test specimens fractured near the interface. On the other hand, the tensile strength of the steel/pure $\mathrm{Mg}$ joint was 66.3MPa without aluminum due to the forced solubility of iron into the magnesium matrix during the FSW. Iron was detected in the magnesium near the interface by STEM-EDS analysis. 


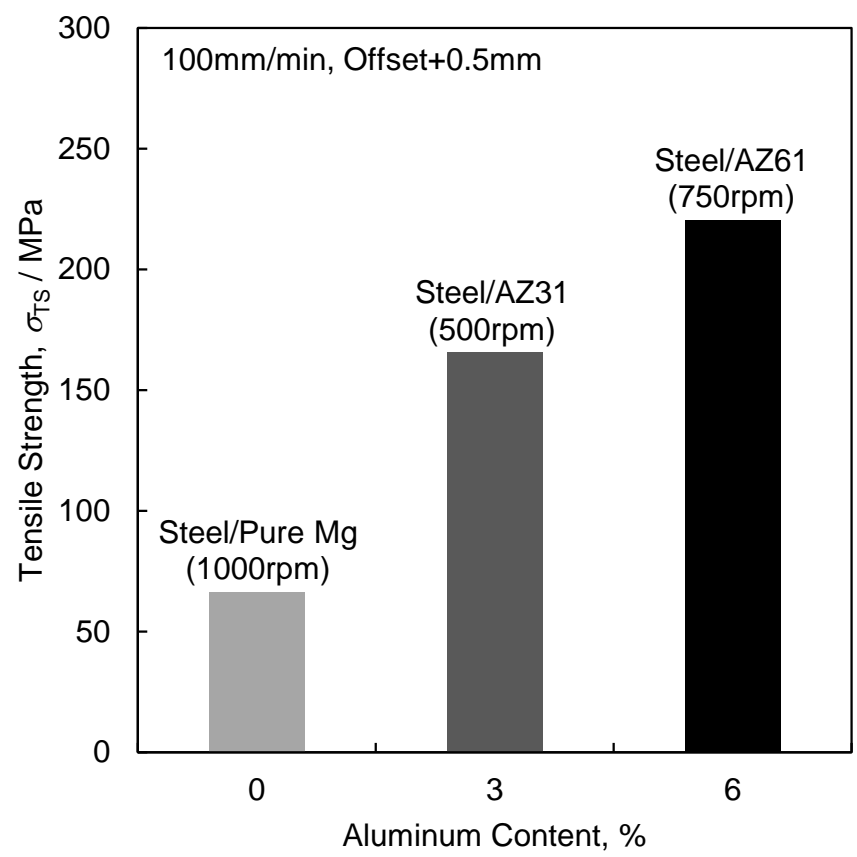

Fig. 4. Relationship between joint the optimal tensile strength and aluminum content. $(100 \mathrm{~mm} / \mathrm{min}$, Offset $+0.5 \mathrm{~mm})$

\subsection{Microstructure of the interface}

Figure 5 shows OM images of the interfaces on the cross section at the tool rotation speed of $1000 \mathrm{rpm}$ and tool offset position of $+0.5 \mathrm{~mm}$. The tip of the probe was flat as shown in Fig. 5. All interfaces were bent, and scattered steel fragments were observed in the magnesium. It is considered that the tool probe created a new surface on the steel plate. 


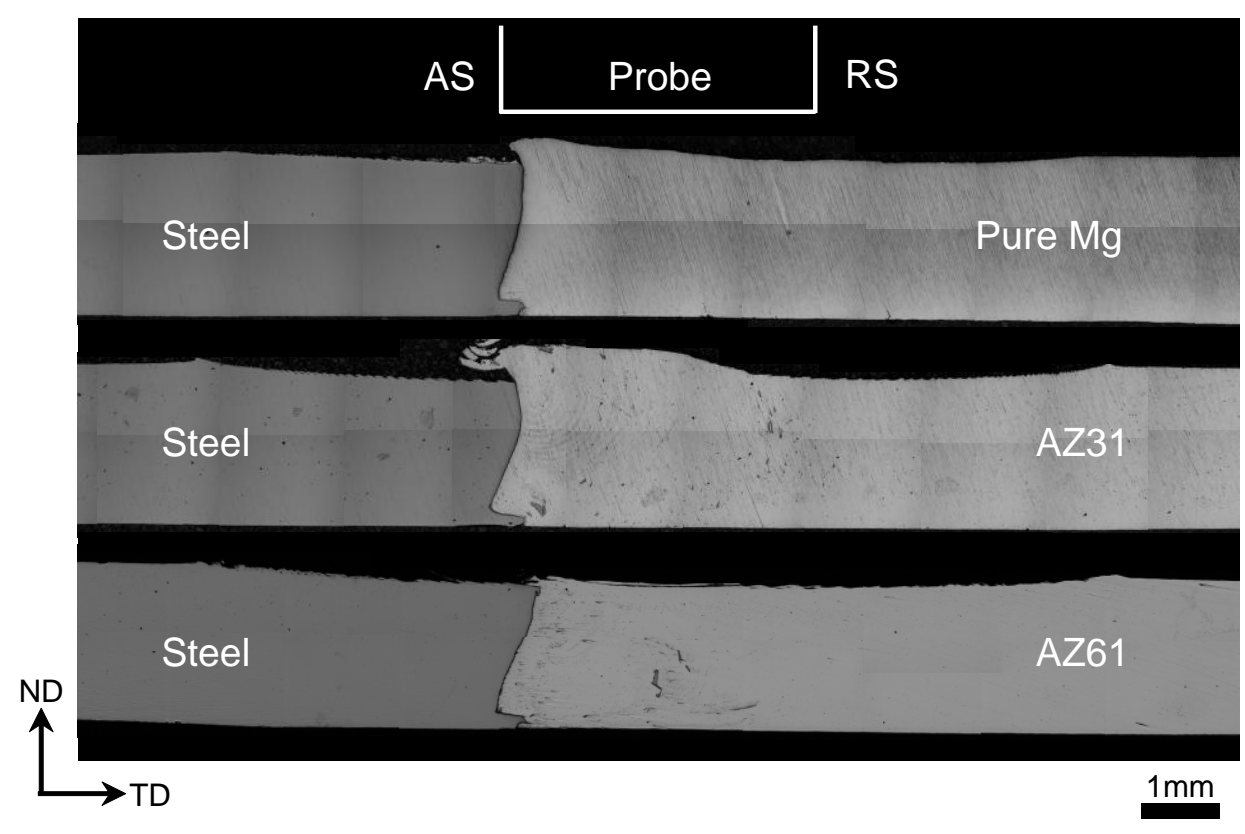

Fig. 5. OM images of the interfaces on the cross section.

(1000rpm, 100mm/min, Offset+0.5mm)

Figure 6 shows SEM images and EDS mappings of the interfaces on the cross section at the tool rotation speed of 1000rpm and at tool offset position of $+0.5 \mathrm{~mm}$. The microstructure observation clarified that the intermetallic compound layer consisting of iron and aluminum formed at the interface of the joint when the magnesium contains aluminum. Therefore, the $\mathrm{Fe}-\mathrm{Al}$ intermetallic compound layer can be obtained by creating a new surface on the steel plate, and the tool probe must come into contact with the steel butt face to form the intermetallic compound. On the other hand, the compound 
was identified as $\mathrm{Fe}_{2} \mathrm{Al}_{5}$ by the quantitative analysis of the STEM-EDS and electron diffraction pattern [21]. The chemical composition of the intermetallic compounds was $20.4 \mathrm{at} \% \mathrm{Fe}-70.3 \mathrm{at} \% \mathrm{Al}-9.0 \mathrm{at} \% \mathrm{Mg}-0.3 \mathrm{at} \% \mathrm{Zn}$.

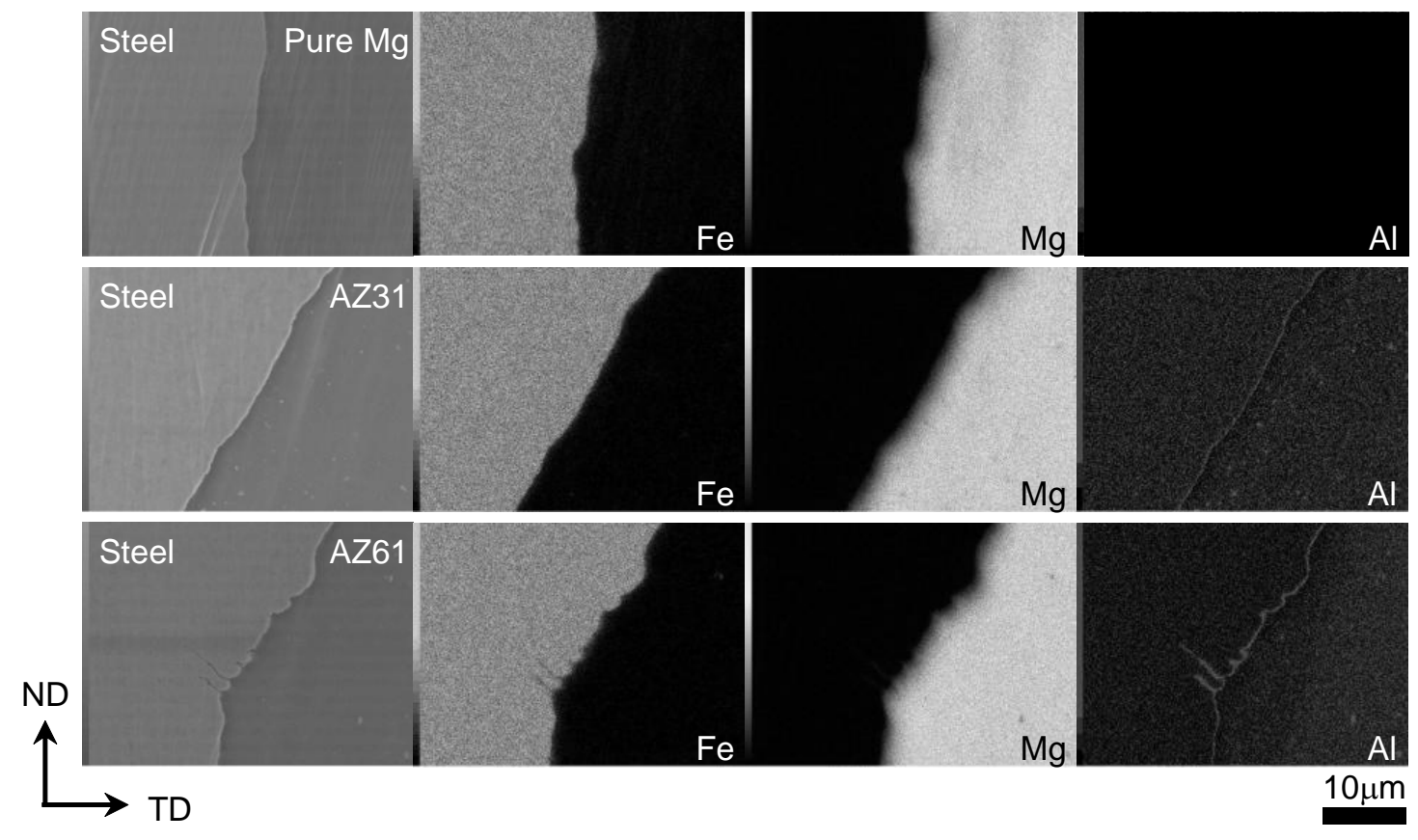

Fig. 6. SEM images and EDS mappings of the interfaces on the cross section.

(1000rpm, 100mm/min, Offset $+0.5 \mathrm{~mm})$ 
Figure 7 shows the relationship between the tensile strength and thickness of the intermetallic compound layer at the tool offset position of $+0.5 \mathrm{~mm}$. The thickness of the intermetallic compound layer was measured on the SEM images. The joint without an intermetallic compound layer, such as the steel/pure Mg joint, showed a low tensile strength. On the other hand, the joints with an intermetallic compound layer such as the steel/AZ31 and steel/AZ61 joint, showed a relatively higher tensile strength. The intermetallic compound layer was thicker at the higher tool rotation speed.

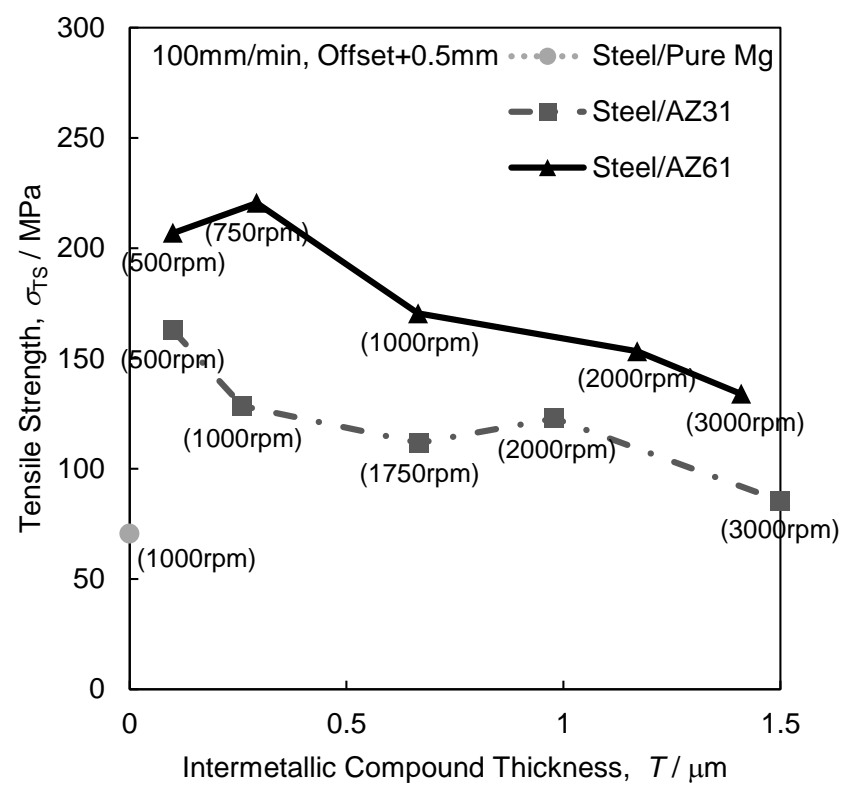

Fig. 7. Relationship between joint tensile strength and thickness of the intermetallic compound layer. ( $100 \mathrm{~mm} / \mathrm{min}$, Offset $+0.5 \mathrm{~mm})$ 
However, the thin intermetallic compound layer of $1.5 \mu \mathrm{m}$ or less was formed even under the high heat input condition by the FSW. These thicknesses should be thin enough to restrain fracture at the intermetallic compounds. In addition, at the same thickness of the intermetallic compound layer, the steel/AZ61 joint was stronger than the steel/AZ31 joint. Therefore, it is considered that the higher aluminum content plays a more significant role in increasing the joint strength.

\subsection{Observation of the fracture surface}

After the tensile test, the fractured surface was observed in order to investigate the fracture position. Figure 8 shows SEM images and EDS mappings of the fracture surface of the joint between steel and AZ31 at the tool offset position of $+0.5 \mathrm{~mm}$. The fracture surfaces of the joint with the thin and thick intermetallic compound layers are shown in Fig.8(a) and (b), respectively. Magnesium was detected on the steel side, while iron was not detected on the magnesium side, regardless of the thickness of the intermetallic compound layer. The fracture surface of the steel/AZ61 joint 
showed the same results as the steel/AZ31 joint.

Therefore, it is considered that the tensile test specimens were mainly fractured on the magnesium side near the interface when the magnesium contained aluminum [22]. This result implies that the magnesium side near the interface was weaker than the intermetallic compound layer, and it determined the tensile strength of the steel/magnesium joint. Additionally,

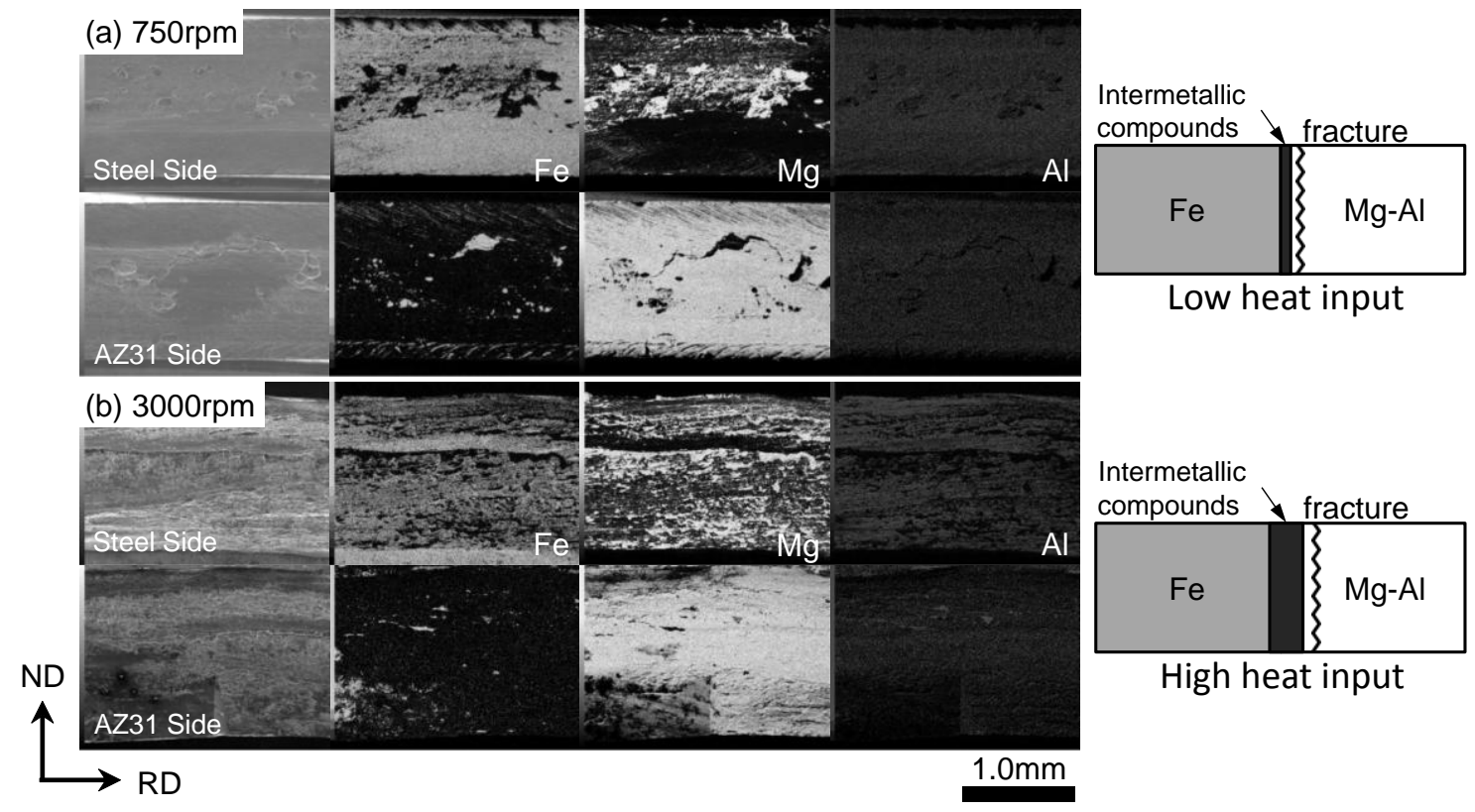

Fig. 8. SEM images and EDS mappings of the fracture surface of the joint between steel and AZ31. (a) 750rpm, (b) 3000rpm 


\subsection{Microstructure near the interface}

Figure 9 shows SEM images and EDS mappings near the interface of the cross section. From the EDS mapping of aluminum and spot analysis of the chemical composition, an aluminum depletion area was formed on the magnesium side near the interface compared to aluminum content of the base magnesium alloy. It is considered that the aluminum in magnesium was consumed by the formation of the $\mathrm{Fe}-\mathrm{Al}$ intermetallic compound. The width of the aluminum depletion layer at the tool rotation speeds of $750 \mathrm{rpm}$ and 3000rpm were $7 \mu \mathrm{m}$ and $18 \mu \mathrm{m}$, respectively. The width of the aluminum depletion layer was larger with the higher heat input.

Figure 10 shows STEM images and EDS mappings near the interface of the cross section. The aluminum contents in the magnesium near the interface at the tool rotation speeds of $750 \mathrm{rpm}$ and $3000 \mathrm{rpm}$ were $-1.5 \mathrm{at} \% \mathrm{Al}$ and -3.0 at $\% \mathrm{Al}$, respectively. The aluminum depletion was significant due to the thicker intermetallic compound layer formed with the higher heat input condition. 


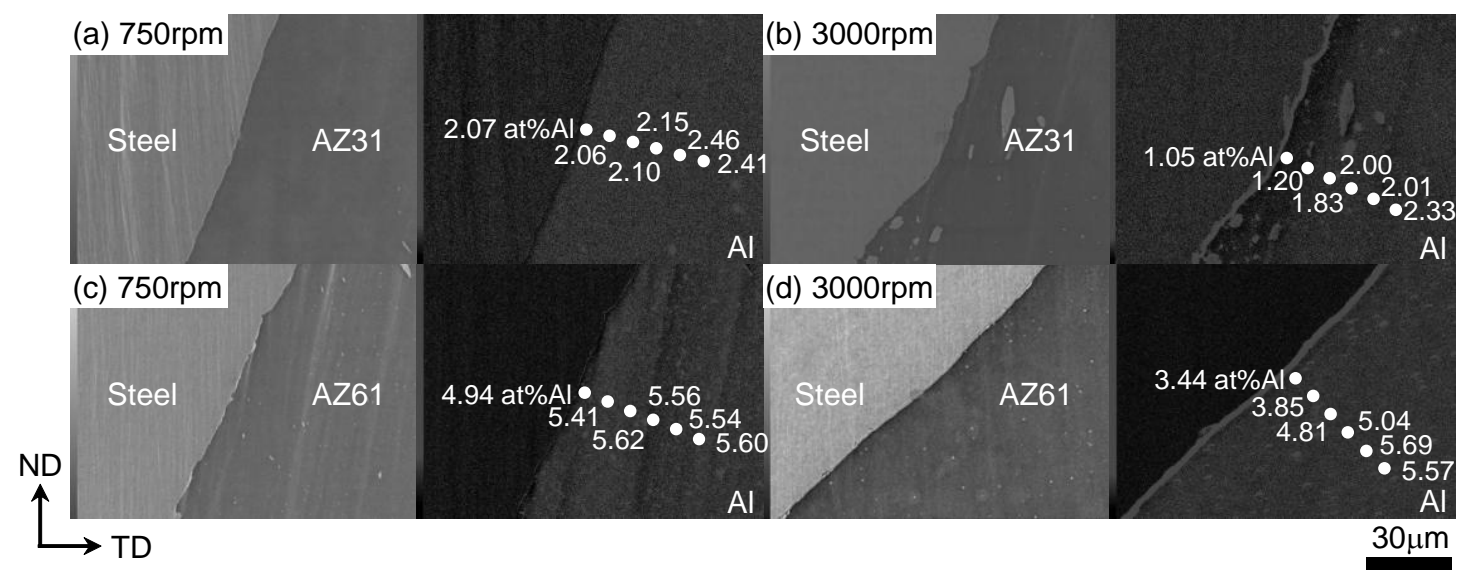

Fig. 9. SEM images and EDS mappings near the interface of the cross section. (a) 750rpm of steel/AZ31, (b) 3000rpm of steel/AZ31, (c) 750rpm of steel/AZ61, (d) 3000rpm of steel/AZ61

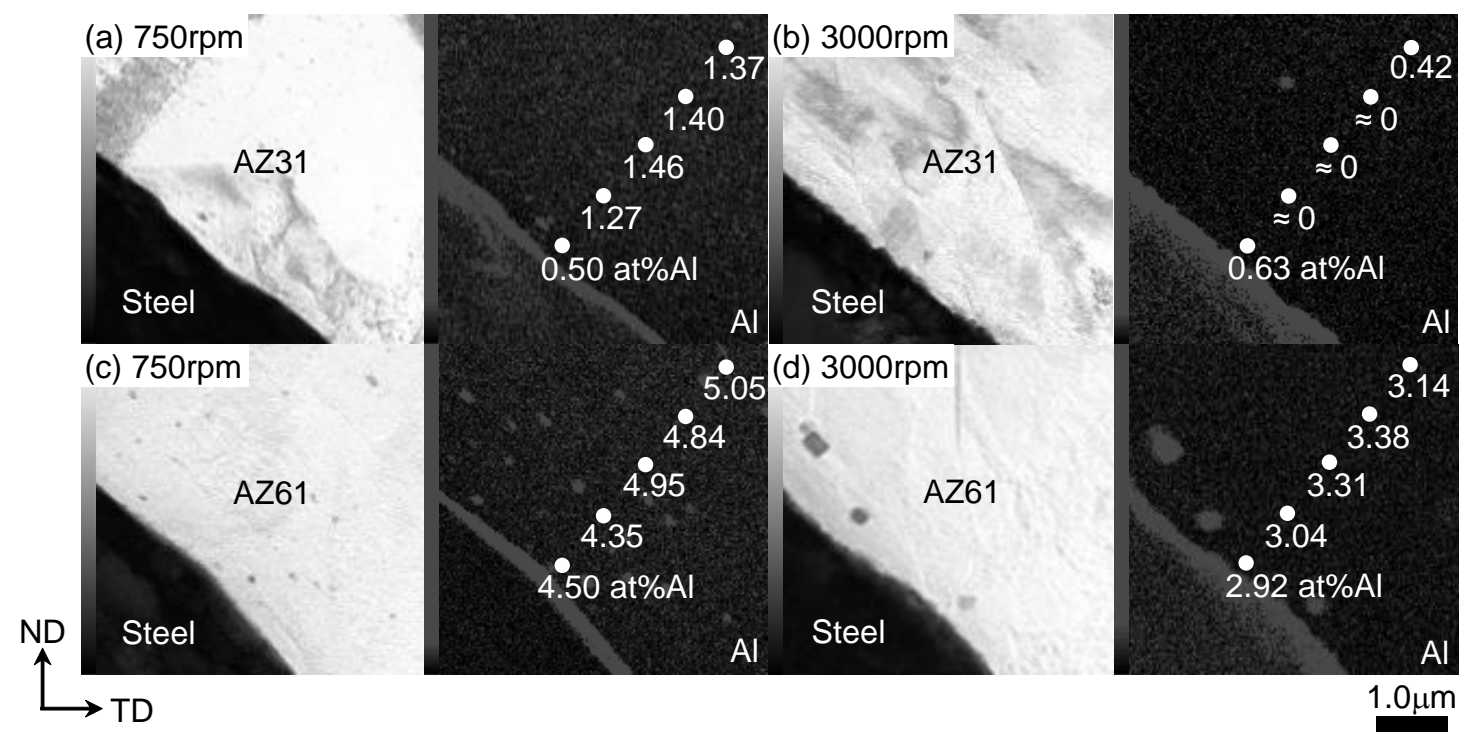

Fig. 10. STEM images and EDS mappings near the interface of the cross section. (a) 750rpm of steel/AZ31, (b) 3000rpm of steel/AZ31, (c) 750rpm of steel/AZ61, (d) 3000rpm of steel/AZ61 
The tensile strength of the magnesium alloy decreases with the decreasing aluminum content. According to the reported relationship between the tensile strength of magnesium alloys and aluminum content in magnesium, the tensile strength decreases by $16 \mathrm{MPa}$ and $42 \mathrm{MPa}$ with the decreses in the aluminum content by 1.5 at\% and 3.0 at\%, respectively [23]. This tendency shows good agreement with the tensile strength measured in this study. This result reveals that both the control of the aluminum depletion and the formation of the thin intermetallic layer at the interface are important to obtain sound steel/magnesium joints of high tensile strength.

\subsection{Effect of surface condition on tensile strength}

The tensile strength of the joint without machining was measured to evaluate the effect of the surface condition on it because the top and bottom surface of the tensile test specimens were cut to understand the effect of the bonding interface on the tensile strength as shown above. Figure 11 shows the relationship between the tensile strength and the surface condition at the tool offset position of $+0.5 \mathrm{~mm}$. The optimal FSW conditions and that led 
to the aluminum depletion were selected. The joint strength between the steel and all types of magnesium alloys without machining decreased only 2 to $10 \mathrm{MPa}$. In addition, there was no significant change of the tendency of the tensile strength with and without machining. Therefore, it is considered that stress concentration on the surface without machining can be negligible to evaluate the effect of the bonding interface on the tensile strength in this study. Additionally, the tensile test specimens of $0.5 \mathrm{~mm}$ thick showed same tensile strength as that of $1.0 \mathrm{~mm}$ thick. This result implies that the effect of thickness of the tensile test specimen on the tensile strength can be negligible in this study.

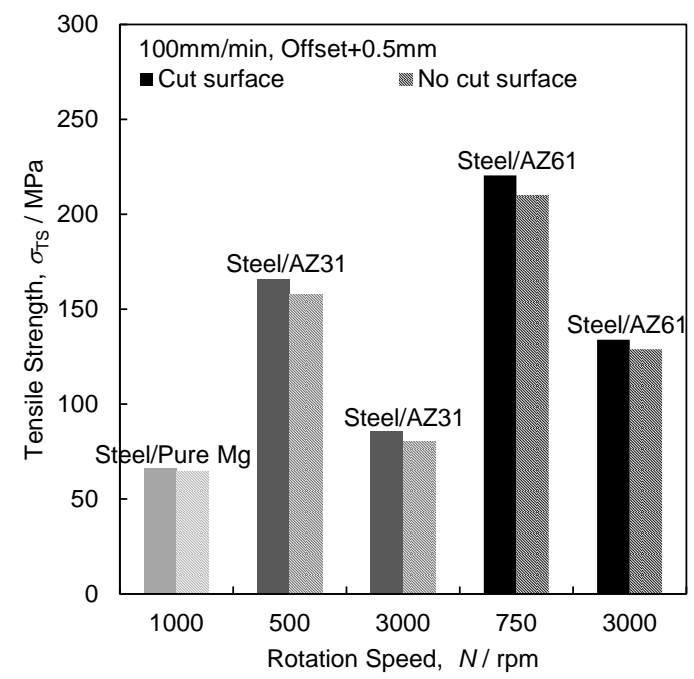

Fig. 11. Relationship between joint tensile strength and surface condition. $(100 \mathrm{~mm} / \mathrm{min}$, Offset $+0.5 \mathrm{~mm})$ 


\section{Conclusions}

Dissimilar FSW joints of immiscible materials (steel/Mg) were successfully formed using aluminum in the magnesium alloy. The microstructure and the tensile strength were evaluated based on the aluminum content. The obtained results can be summarized as follows.

(1) An Fe-Al intermetallic compound $\left(\mathrm{Fe}_{2} \mathrm{Al}_{5}\right)$ layer was formed at the interface of the joint when the magnesium contains aluminum. The tool probe must come into contact with the steel butt face to form the optimal intermetallic compound layer.

(2) The steel/magnesium joint strength increased with the increasing aluminum content of the magnesium alloy and thinner intermetallic compound layer.

(3) The steel/magnesium joint formed under the optimal FSW condition fractured on the magnesium side near the interface.

(4) The aluminum depletion on the magnesium side near the interface was significantly correlated to the tensile strength of the steel/magnesium joint. The low heat input during the FSW restrained the aluminum 
depletion, which led to the higher tensile strength.

\section{Acknowledgements}

The present study was supported by Collaborative Research, "Heterogeneous Structure Control" in the Japan Science and Technology Agency, and Grant-in-Aid from the Ministry of Education, Culture, Sports, Science and Technology (MEXT), Japan. 


\section{References}

[1] International Energy Agency, Energy efficiency publications (2007) $18-24$.

[2] Y.D. Chung, H. Fujii, Y. Sun, H. Tanigawa, Materials Science \& Engineering A 528 (2011) 5812-5821.

[3] Y.F. Sun, H. Fujii, N. Tsuji, Materials Science \& Engineering A 585 (2013) 17-24.

[4] Y.F. Sun, H. Fujii, N. Takaki, Y. Okitsu, Materials and Design 47 (2013) 350-357.

[5] Y.F. Sun, H. Fujii, Intermetallics 33 (2013) 113-119.

[6] M. Aonuma, K. Nakata, Materials Science \& Engineering B 161 (2009) 46-49.

[7] Y. S.Sato, S. H. C. Park, M. Michiuchi, H. Kokawa, Scripta Materialia 50 (2004) 1233-1236.

[8] C. M. Chen, R. Kovacevic, Machine Tools \& Manufacture 44 (2004) $1205-1214$

[9] H. Uzun, C. D. Donne, A. Argagnotto, T. Ghidini, C. Gambaro, Materials and Design 26 (2005) 41-46.

[10] M. Fukumoto, T. Subaki, Y. Shimoda, T. Yasui, Q. J. Jpn. Weld. Soc. 22-2 (2004) 309-314.

[11] T. Tanaka, T. Morishige, T. Hirata, Scripta Materialia 61 (2009) 756-759.

[12] T. B. Massalski (Ed.), Binary Alloy Phase Diagrams, (ASM, Metals Park, Ohio 1990) 147. 
[13] T. Watanabe, K. Kagia, A. Yanagisawa, H. Tanabe, Q. J. Jpn. Weld. Soc. 24-1 (2006) 108-115.

[14] C. Schneider, T. Weinberger, J. Inoue, T. Koseki, N. Enzinger, Science and Technology of Welding and Joining 16-1 (2011) 100-106.

[15] Y.C. Chen, K. Nakata, Materials and Design 30 (2009) 3913-3919.

[16] R. Ninomiya, H. Yukawa, M. Morinaga, K. Kuota, Journal of Alloys and Compounds 215 (1994) 315.

[17] H.Fujii, L.Cui, N.Tsuji, M.Maeda, K.Nakata and K.Nogi, Mater. Sci. Eng. A, 429 (2006) 50-57.

[18] T. Nagaoka, Y. Morisada, H. Fujii and M. Hukuoka, Science and industry 83 (2009) 337-342.

[19] T. Watanabe, H. Takayama, A. Yanagisawa, Journal of Materials Processing Technology 178 (2006) 342-349.

[20] R.S. Coelho, A.Kostka, J.F.dosSantos, A.Kaysser-Pyzalla, Materials Science \& Engineering A 556 (2012) 175-183.

[21] M. Dehghani, A. Amadeh, S.A.A. Akbari Mousavi, Materials and Design 49 (2013) 433-441.

[22] T. Araki, M. Koba, S. Nambu, J, Inoue, T, Koseki, Materials Transactions 52-3 (2011) 568-571.

[23] J.C. McDonald, Trans. AIME 137 (1940) 430. 


\section{Figure caption}

Figure $1 \mathrm{Fe}-\mathrm{Al}$ and $\mathrm{Fe}-\mathrm{Mg}$ phase diagrams.

Figure 2 Schematic illustrations of applied friction stir welding process.

Figure 3 Relationship between joint tensile strength and tool offset position. (1000rpm, 100mm/min)

Figure 4 Relationship between joint the optimal tensile strength and aluminum content.

Figure 5 OM images of the interfaces on the cross section. (1000rpm, $100 \mathrm{~mm} / \mathrm{min}$, Offset $+0.5 \mathrm{~mm})$

Figure 6 SEM images and EDS mappings of the interfaces on the cross section. (1000rpm, 100mm/min, Offset+0.5mm)

Figure 7 Relationship between joint tensile strength and thickness of the intermetallic compound layer. ( $100 \mathrm{~mm} / \mathrm{min}$, Offset $+0.5 \mathrm{~mm})$

Figure 8 SEM images and EDS mappings of the fracture surface of the joint between steel and AZ31. (a) 750rpm, (b) 3000rpm

Figure 9 SEM images and EDS mappings near the interface of the cross section. (a) 750rpm of steel/AZ31, (b) 3000rpm of steel/AZ31, (c) 750rpm of steel/AZ61, (d) 3000rpm of steel/AZ61

Figure 10 STEM images and EDS mappings near the interface of the cross section. (a) 750rpm of steel/AZ31, (b) 3000rpm of steel/AZ31, (c) 750rpm of steel/AZ61, (d) 3000rpm of steel/AZ61

Figure 11 Relationship between joint tensile strength and surface condition. (100mm/min, Offset+0.5mm) 